\title{
Spatial scale affects the relative role of stochasticity versus determinism in soil bacterial communities in wheat fields across the North China Plain
}

Yu Shi ${ }^{1+}$, Yuntao $\mathrm{Li}^{1+}$, Xingjia Xiang ${ }^{1}$, Ruibo Sun ${ }^{1}$, Teng Yang ${ }^{1}$, Dan $\mathrm{He}^{1}$, Kaoping Zhang ${ }^{1}$, Yingying $\mathrm{Ni}^{1}$, Yong-Guan Zhu' ${ }^{2}$, Jonathan M. Adams ${ }^{3}$ and Haiyan Chu ${ }^{1 *}$

\begin{abstract}
Background: The relative importance of stochasticity versus determinism in soil bacterial communities is unclear, as are the possible influences that alter the balance between these. Here, we investigated the influence of spatial scale on the relative role of stochasticity and determinism in agricultural monocultures consisting only of wheat, thereby minimizing the influence of differences in plant species cover and in cultivation/disturbance regime, extending across a wide range of soils and climates of the North China Plain (NCP). We sampled 243 sites across $1092 \mathrm{~km}$ and sequenced the $16 \mathrm{~S}$ rRNA bacterial gene using MiSeq. We hypothesized that determinism would play a relatively stronger role at the broadest scales, due to the strong influence of climate and soil differences in selecting many distinct OTUs of bacteria adapted to the different environments. In order to test the more general applicability of the hypothesis, we also compared with a natural ecosystem on the Tibetan Plateau.

Results: Our results revealed that the relative importance of stochasticity vs. determinism did vary with spatial scale, in the direction predicted. On the North China Plain, stochasticity played a dominant role from 150 to $900 \mathrm{~km}$ (separation between pairs of sites) and determinism dominated at more than $900 \mathrm{~km}$ (broad scale). On the Tibetan Plateau, determinism played a dominant role from 130 to $1200 \mathrm{~km}$ and stochasticity dominated at less than $130 \mathrm{~km}$. Among the identifiable deterministic factors, soil pH showed the strongest influence on soil bacterial community structure and diversity across the North China Plain. Together, $23.9 \%$ of variation in soil microbial community composition could be explained, with environmental factors accounting for $19.7 \%$ and spatial parameters $4.1 \%$.

Conclusions: Our findings revealed that (1) stochastic processes are relatively more important on the North China Plain, while deterministic processes are more important on the Tibetan Plateau; (2) soil pH was the major factor in shaping soil bacterial community structure of the North China Plain; and (3) most variation in soil microbial community composition could not be explained with existing environmental and spatial factors. Further studies are needed to dissect the influence of stochastic factors (e.g., mutations or extinctions) on soil microbial community distribution, which might make it easier to predictably manipulate the microbial community to produce better yield and soil sustainability outcomes.
\end{abstract}

Keywords: Deterministic, Stochastic, Bacterial diversity, $\beta N T I$, Soil pH, PCNM

\footnotetext{
* Correspondence: hychu@issas.ac.cn

${ }^{\dagger}$ Equal contributors

${ }^{1}$ State Key Laboratory of Soil and Sustainable Agriculture, Institute of Soil

Science, Chinese Academy of Sciences, 71 East Beijing Road, Nanjing 210008,

China

Full list of author information is available at the end of the article
} 


\section{Background}

Soil microbial diversity patterns have been well documented in a wide variety of habitats [1-3]. From an initial focus on the description of patterns, attention is now turning towards the underlying processes influencing the structure of microbial communities [4, 5]. Cropland soils represent a relatively neglected area in terms of both patterns and processes in microbial community ecology. Despite the importance of cropland soils for global food supply, there has been relatively little attention paid in understanding what processes influence the structure of microbial distribution patterns [6-8]. Understanding the structuring of soil communities could have practical implications for crop productivity and food production [9-11].

In attempting to understand the factors giving structure to natural and agricultural soil microbial communities, studies have emphasized two fundamental types of process: (1) Deterministic processes, whereby species of bacteria occur wherever there is a unique potential niche in which they can survive in the face of competition [12]. In its "extreme" form, each species is predictably present wherever a suitable niche exists. This has been summarized as "everything is everywhere, but the environment selects" [13]. (2) Stochastic processes, whereby many species exist in the same or strongly overlapping niches, but do not eliminate one another due to their competitive abilities being closely balanced (in accordance with neutral theory [14]). In this situation, the relative abundance of species drifts with chance fluctuations in populations. Stochastic processes also include the legacy of past disturbance events causing more dramatic nonselective crashes in populations, followed by the vagaries of dispersal events leading to species arriving unpredictably. In an extreme stochastic scenario, bacterial species are often absent from places in which they could potentially survive in abundance, and those species present are only there following chance arrival and persistence $[15,16]$.

There is little doubt that bacterial communities are in reality the result of combinations of both stochastic and deterministic processes, and only the relative importance of each is in dispute $[4,5]$. There are many features of bacterial community composition and diversity that certainly involve determinism, because they are highly predictable in terms of environmental factors [17, 18]. Important deterministic factors, at least at the higher taxonomic level, include soil $\mathrm{pH}$ [17-20], soil moisture [21], availability of nutrients [22, 23], soil C:N ratio [3, 24, 25] and soil temperature [26], and biotic factors such as plant diversity and type [27-33]. Other studies have suggested a role for stochastic processes in dispersal limitation, past environmental conditions, mutations, and spatial distance, all of which can have a strong influence on the distribution of microbial communities [34-39]. In addition, some studies have investigated the driving process for microbial communities at different spatial scales. For example, at the small scale (centimeters to meters) [40,41], spatial autocorrelation of microbial community structure is observed, and Bru et al. [42] found that this was also the case at the landscape scale at a pair to pair distance $>700 \mathrm{~km}$. Functional microbial communities in arctic soils are significantly influenced by spatial factors at a large scale [43]. However, few studies have compared the relative role of stochastic and deterministic processes across different spatial scales.

In recent years, more powerful statistical techniques have become available for discerning the relative importance of deterministic and stochastic processes in bacterial community structure. These include Mean Nearest Taxon Distance (MNTD), Nearest Taxon Index (NTI), Beta MNTD, Beta NTI [4], and zero-sum multinomial (ZSM) [16]. Usually, phylogenetic turnover within communities belonging to a single sample is quantified using MNTD and NTI, and turnover in phylogenetic composition across temporal and spatial scales (phylogenetic $\beta$ diversity) is quantified using $\beta$ MNTD and $\beta$ NTI [4]. For example, these methods have been used to compare the role of deterministic and stochastic processes in mediating microbial succession over 105 years of ecosystem development [5], quantifying community assembly processes in subsurface water and sediments [4, 44, 45], and taxonomic and functional microbial community selection processes in rhizosphere soils [46]. However, most studies conducted to date have focused on temporal (time-related) changes and been conducted in natural ecosystems. There has been relatively little study of the role of determinism vs. stochasticity across varying spatial scales and in agricultural systems. Understanding the role of determinism may help to correlate yield with microbial community composition. If certain microbial communities have an important role in enhancing yields, it may be possible to improve yields on a broad scale by encouraging these specific communities. However, for this to be effective, there must be a strong role for determinism to replicate and produce such communities reliably. In this study, we chose an agricultural system, partly for the practical implications in understanding community processes, but also as a relatively simplified system which might offer broader clues to how microbial communities work in general, including in natural soil environments.

The North China Plain (NCP) was chosen as our study area, which is the most important food-producing region in Asia, accounting for over $50 \%$ of total cereal production in China [47]. It is estimated that more than $15 \%$ of total annual grain production and over $19 \%$ of total winter wheat production in China are contributed by this area [47-50]. Over the past century, wheat-maize double 
cropping rotation has been the dominant cropping system, supported by irrigation, fertilizer use, and appropriate crop varieties $[23,51,52]$. In the present work, using the Illumina Miseq platform, we surveyed 243 wheatmaize rotation soils across the NCP at a standardized point in the cropping cycle. We hypothesized that determinism would play a relatively stronger role at broader scales, due to the strong influence of climate and soil differences in selecting distinct OTUs of bacteria adapted to different environments. In order to understand the differences in the relative role of deterministic and stochastic processes between arable soils and natural ecosystems, Tibetan Plateau soils were chosen as a case study for comparison.

\section{Results}

\section{Soil bacterial community composition of the North China} Plain

Based on Illumina next-generation sequencing technologies, we obtained 15,184,073 quality sequences for 243 soils from wheat-maize cropping rotation systems across the NCP and identified 75,179 operational taxonomic units $[97 \%$ similarity, mostly bacteria $(\sim 99.7 \%)$ and a few archaea $(\sim 0.3 \%$, most were Thaumarchaeota)]. At the phyla/class level, Actinobacteria ( 24\%), Alphaproteobacteria ( 12\%), Acidobacteria ( 14\%), Gammaproteobacteria $(\sim 10 \%)$, Betaproteobacteria $(\sim 8 \%)$, and Chloroflexi $(\sim 8 \%)$ were dominant, accounting for more than $75 \%$ of total sequences (Additional file 1: Figure S1; Additional file 2: Tables S1 and S2). In addition, Deltaproteobacteria, Gemmatimonadetes, Planctomycetes, Bacteroidetes, Nitrospirae, and Firmicutes were ubiquitous in the investigated soils and present in high relative abundance in some soils (Additional file 2: Table S1). Additionally, 34 rare phyla were identified (Additional file 2: Table S1).

\section{Deterministic processes control local community composition of the North China Plain}

Across all sites, we found that values of standardized effect sizes of MNTD (NTI) calculated using the null model were negative (Additional file 1: Figure S2, $P<$ 0.05), suggesting bacterial communities within samples were more influenced by niche processes than dispersal limitation. In addition, based on the AIC values, the fitness of ZSM, pre-emption, broken stick, log-normal, and Zipf-Mandlebrot models were compared to investigate which processes were important in shaping bacterial community structure. The results showed that the Mandlebrot model best fitted the data for NCP soils (Additional file 1: Figure S3), which is consistent with the MNTD analysis and indicates that the main driving process at the local scale was in accordance with the niche-based theory.
Deterministic and stochastic processes have different roles in controlling community dynamics at different spatial scales

In general, we found that the soil bacterial community decreased in similarity with increasing spatial distance and increasingly environmental dissimilarity (Additional file 1: Figure S4). In order to establish which process controls community dynamics at different spatial scales, $\beta$ NTI values were determined. The results showed that the stochastic process was dominant at scales $1,2,3,4$, $5,6,7,8,9,10,11$, and 13 (Table 1; Fig. 1; values $>-2$ and $<2$ ). Among these scales, $1,2,3$, and 4 are at the small spatial scale, while $5,6,7,8,9,10$, and 11 are at the medium spatial scale. At the large spatial scale (> $800 \mathrm{~km}$ ), all scales except scale 13 were dominated by deterministic processes (values $<-2$ ), which had a strong impact on the phylogenetic turnover pattern across the sites. After quantifying the relative contribution of deterministic and stochastic process for each spatial scale (the proportion of $\beta$ NTI values $>-2$ and $<2$ and $\beta$ NTI values $<-2$ and $>2$ ), we found that deterministic process provided over $50 \%$ contribution at scales $12,14,15$, and 16 , while stochasticity provided over $50 \%$ contribution at the small and median scales (Table 1).

We compared the relative role of deterministic and stochastic processes between the North China Plain and Tibetan Plateau at different spatial scales. On the Tibetan Plateau, stochastic processes were dominant at

Table 1 Variation in median $\beta$ NTI values at different spatial scales and the relative contribution (\%) of deterministic and stochastic process in each spatial scale of the North China Plain

\begin{tabular}{lllll}
\hline $\begin{array}{l}\text { Spatial } \\
\text { scale }\end{array}$ & $\begin{array}{l}\text { Spatial distance } \\
(\mathrm{km})\end{array}$ & $\begin{array}{l}\text { Median } \beta N T I \\
\text { values }\end{array}$ & Deterministic(\%) & Stochastic(\%) \\
\hline $\mathbf{1}$ & 35.58 & -1.41 & 34.05 & 65.95 \\
$\mathbf{2}$ & 106.16 & -1.44 & 33.94 & 66.06 \\
$\mathbf{3}$ & 176.75 & -1.54 & 36.53 & 63.47 \\
$\mathbf{4}$ & 247.33 & -1.66 & 39.94 & 60.06 \\
$\mathbf{5}$ & 317.91 & -1.7 & 41.23 & 58.77 \\
$\mathbf{6}$ & 388.5 & -1.57 & 37.36 & 62.64 \\
$\mathbf{7}$ & 459.08 & -1.58 & 38.37 & 61.63 \\
$\mathbf{8}$ & 529.66 & -1.52 & 35.63 & 64.37 \\
$\mathbf{9}$ & 600.25 & -1.56 & 38.83 & 61.17 \\
$\mathbf{1 0}$ & 670.83 & -1.58 & 38.17 & 61.83 \\
$\mathbf{1 1}$ & 741.42 & -1.59 & 38.66 & 61.34 \\
12 & 812 & -2.42 & 59.86 & 40.14 \\
$\mathbf{1 3}$ & 882.58 & -1.44 & 34.73 & 65.27 \\
14 & 953.17 & -2.39 & 53.09 & 46.91 \\
15 & 1023.8 & -2.83 & 74.69 & 25.31 \\
16 & 1094.3 & -2.74 & 61.11 & 38.89 \\
\hline
\end{tabular}

Spatial scale values in bold indicate that stochastic processes are dominant, while normal font indicates that deterministic processes are dominant 


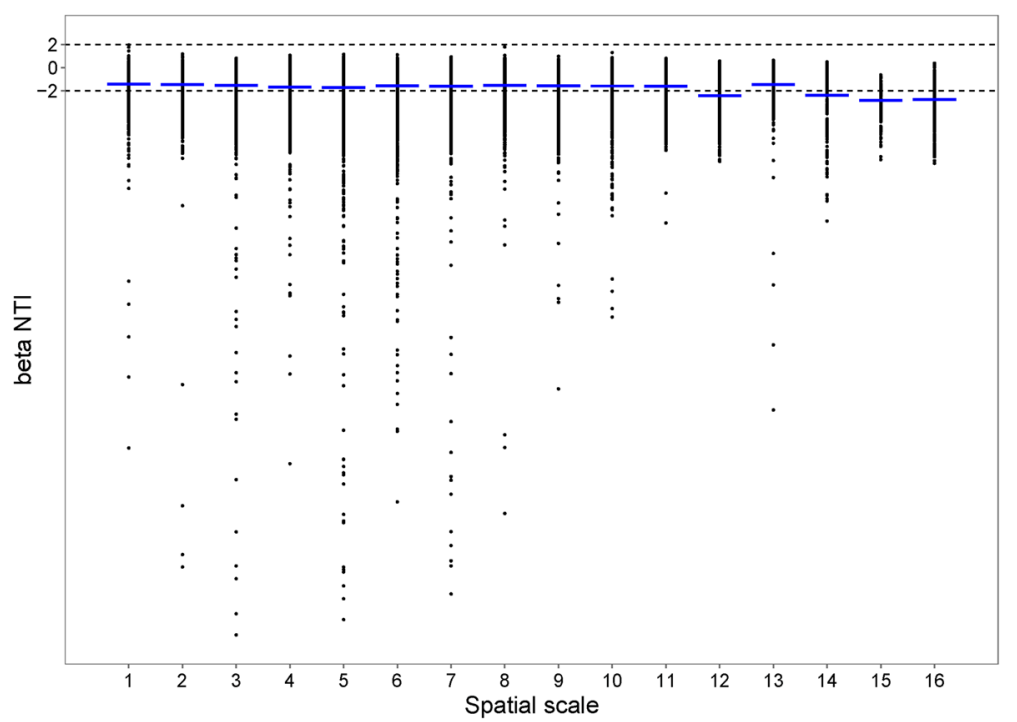

Fig. 1 Scatter plot of $\beta N T I$ values grouped by spatial scales of the North China Plain. Dash blue lines represent the median value of each scale

scales 1 and 2 (Additional file 1: Figure S5; Additional file 2: Table S3; values $>-2$ and $<2$ ), while deterministic processes were dominant at scales $3,4,5,6,7,8,9,10$, 11, 12, 13, and 14 (Additional file 1: Figure S5). Among these scales, 1,2 , and 3 are at small scale, while 4, 5, 6, $7,8,9$, and 10 are at medium spatial scale. Scales 11,12 , 13,14 , and 15 are at large spatial scale $(>800 \mathrm{~km})$ (Additional file 2: Table S3). This indicated that deterministic process provided over $50 \%$ contribution at medium and large scales on the Tibetan Plateau, while in the North China Plateau, deterministic processes were only dominant at large scales.

\section{Deterministic factors in soil bacterial community} distribution of the North China Plain

In order to visualize the soil bacterial distribution pattern, bacterial community composition in wheat soils across the NCP was represented using non-metric multidimensional scaling plots based on Bray-Curtis dissimilarity (Fig. 2). The ordination plot clearly indicates that soil bacterial community composition across the NCP is distributed according to the soil $\mathrm{pH}$ gradient. This interpretation was confirmed by correlation analyses between Bray-Curtis distances and soil $\mathrm{pH}$ using the Mantel test $(r=0.8, p=0.001$, Additional file 2: Table S4), DistLM

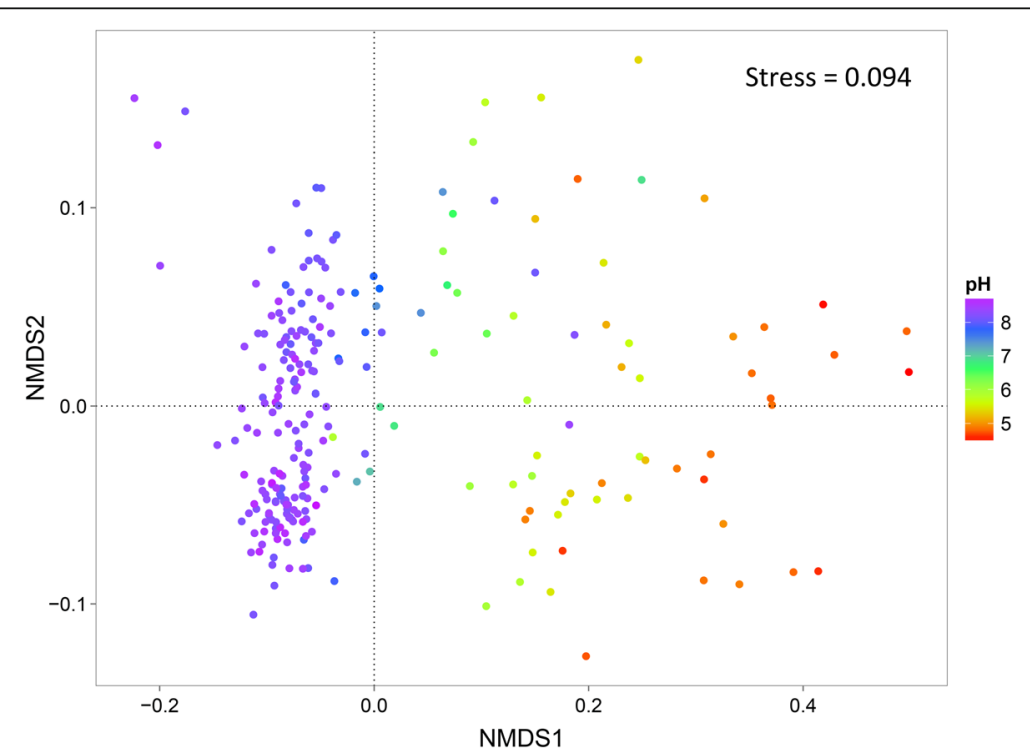

Fig. 2 Bacterial community compositional structure in the North China Plain (NCP) wheat soils, as indicated by non-metric multidimensional scaling plots. Sites are color-coded according to the soil pH gradient 
(Additional file 2: Table S5) and Multivariate Regression Trees (MRT; Additional file 1: Figure S6). In addition to soil $\mathrm{pH}$, other soil factors such as magnesium $(\mathrm{Mg})$, calcium (Ca), total phosphorus (TP), total potassium (TK), manganese (Mn), arsenic (As), potassium (K), cadmium $(\mathrm{Cd})$, zinc $(\mathrm{Zn})$, available phosphorus (AP), and Ferrum $(\mathrm{Fe})$ also showed a significant relationship with the soil bacterial community (Additional file 2: Table S4). Regardless of Bray-Curtis dissimilarity, we found that bacterial phylogenetic diversity (PD), OTUs, Chao1, Shannon, and Simpson E indexes, which represent the $\alpha$-diversity, were significantly increased with increasing soil $\mathrm{pH}$ and $\mathrm{TP}$, with soil $\mathrm{pH}$ having the strongest influence on bacterial diversity (Fig. 3), followed by $\mathrm{Mg}, \mathrm{Ca}$, $\mathrm{TP}, \mathrm{Cd}$, and EC (electrical conductivity). Other factors such as organic carbon (OC), total nitrogen (TN), dissolved organic carbon (DOC), and $\mathrm{Mn}$ were negatively correlated with bacterial diversity (Additional file 2: Table S6). Together, these results strongly suggest that soil $\mathrm{pH}$ is a key factor controlling soil bacterial community structure and diversity across the NCP.

Interestingly, when we included the mean annual precipitation (MAP) and mean annual temperature (MAT) from World Clim-Global Climate Data (www.worldclim.org), and the Mantel test, both MAP ( $r=0.54, p=$ $0.001)$ and MAT $(r=0.28, p=0.001)$ showed a significant relationship with the soil microbial community composition (Additional file 2: Table S7).

\section{Contribution of environmental and spatial parameters to variation in soil microbial community of the North China Plain}

As shown in Fig. 4, 23.9\% of variation in the undetrended soil microbial data (see "Method" in [53] and

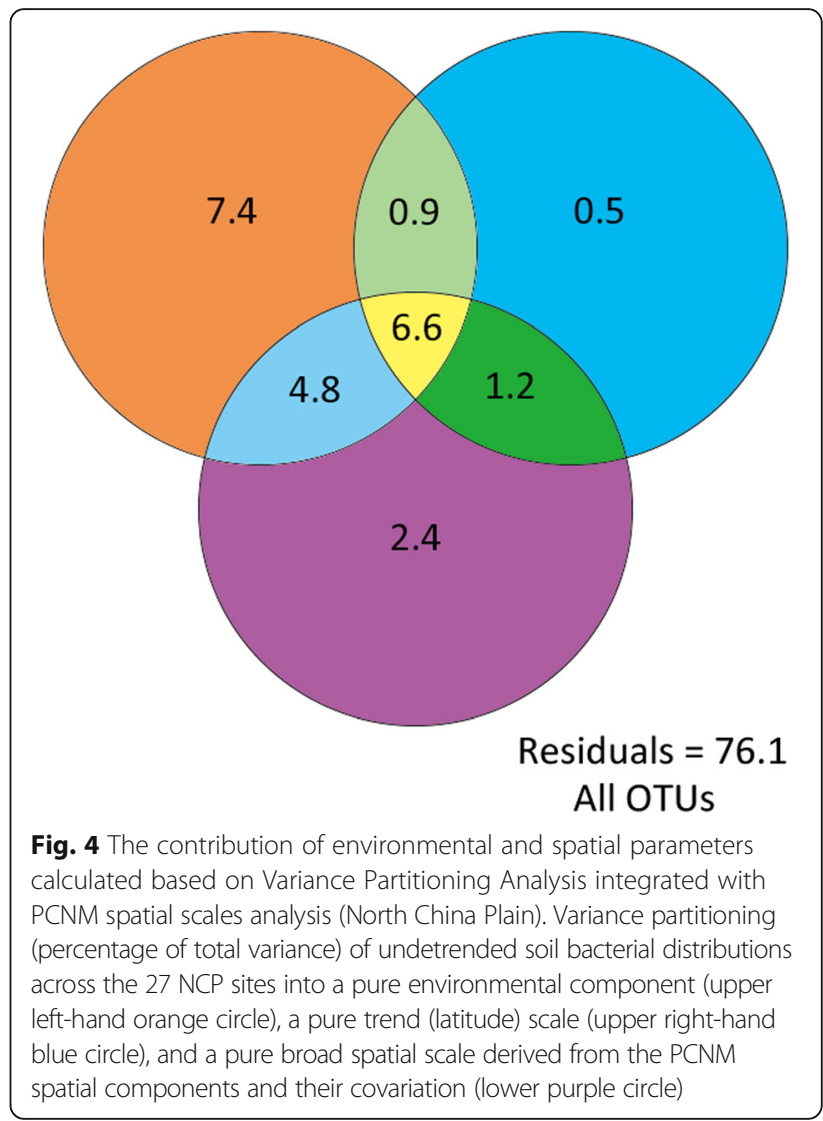

the modified diagram illustrating the variance partitioning outputs of the PCNM analysis in Additional file 1: Figure S9 in the supporting information of [43]) could be explained by environmental factors, linear trend, and spatial scale. Spatial scale plus linear trend contributed $4.1 \%$ of variation in soil microbial data, and

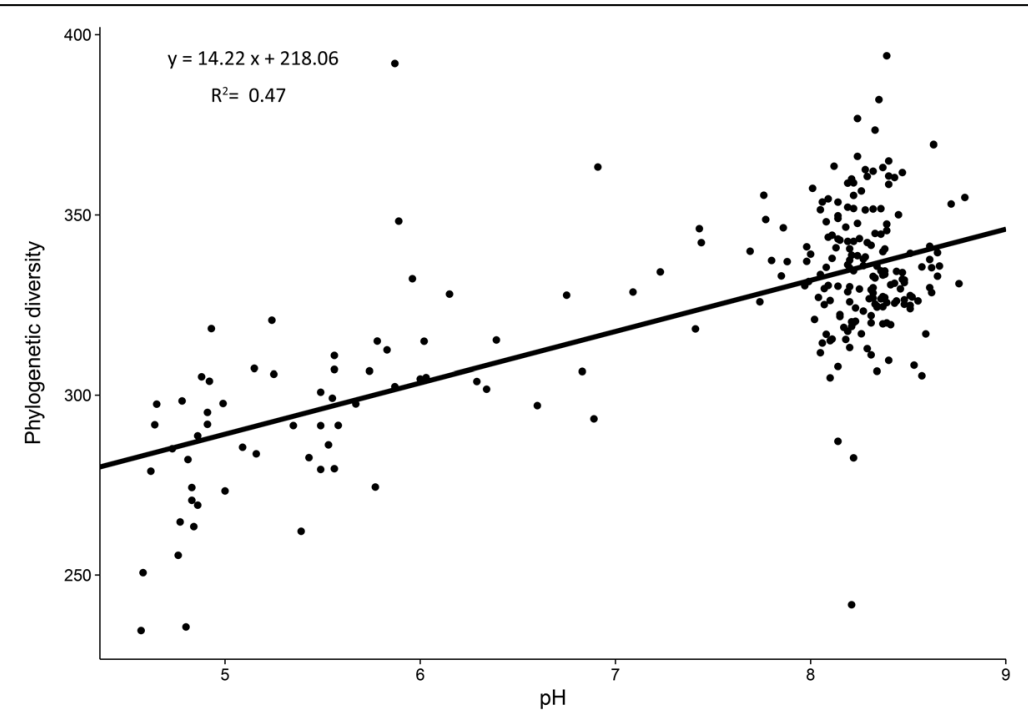

Fig. 3 Relationship between soil pH and bacterial phylogenetic diversity of the North China Plain 
environmental soil factors accounted for 19.7\% (12.3\% was spatially structured). Also, $6.6 \%$ could be attributed to the interaction between environmental variables and spatial parameters (Fig. 4), demonstrating the strong influence of spatial scale and environmental variables. However, a large proportion of the variation (76.1\%) across all bacterial data could not be explained by model parameters or by interactions between them.

\section{Discussion}

Is determinism more important at larger scales? In our study, we found that on more local scales, the soil microbial community of the North China Plain (starting at around $35 \mathrm{~km}$ separation between samples) is more strongly influenced by stochastic factors such as ecological drift, mutation, and random births-deaths [4, 54, 55], compared with larger scales (up to $1094 \mathrm{~km}$ separation). By comparison in the natural ecosystem of the Tibetan Plateau, stochastic process only dominated at scales of less than $130 \mathrm{~km}$ (Additional file 1: Figure S5). There is some variability in the results either side of the borderline ( $\beta$ NTI -2$)$ as scale increases, but upon comparing the results at different scales by regression, there is an overall trend towards determinism at broader scales (Fig. 1). There is, however, a clear jump in $\beta$ NTI towards values below -2 , at scales beyond about $800 \mathrm{~km}$ separation between data points (Fig. 1). These findings are consistent with our prediction that deterministic influences are more likely to dominate at a larger scale, since deterministic structuring provided by strong environmental gradients, which require distinct niches and adaptations for survival, is more likely to be present. Among the most clearly identifiable deterministic structuring factors was soil pH (Fig. 2). Thus, the effect of spatial scale on the relative importance of determinism and stochasticity was broadly as predicted. If two places are so environmentally distinct that few of their bacterial OTUs are interchangeable, differences in their community composition are predictable and can be assigned to deterministic processes. It is only at the local scale, where the environment is homogenous enough that most OTUs can survive everywhere, that stochastic effects begin to dominate. These findings are also consistent with other $\beta$ NTI studies investigating the driving processes in aquatic habitats [45] or seawater ecosystems [56].

In a succession study involving stable local scale conditions, stochasticity appeared to dominate $[5,57]$. Similarly, in a PCNM study in a cool temperate forest ecosystem by Bahram et al. [58], eukaryote community variation was dominated by stochasticity at a local scale. The forest site in this previous study was also a homogenous environment in which stochasticity is likely to dominate. Thus, it is not surprising to find stochasticity playing a relatively important role at the local scale, especially in habitats that are fairly homogenous with few environmental differences to drive deterministic niche differentiation $[59,60]$. Compared to the wide expanse of flat land of the North China Plain, the Tibetan Plateau had more varied terrain and habitats [21], which would be expected to give greater heterogeneity in the Tibetan Plateau soil. Thus, determinism began to dominate at the somewhat smaller spatial distance of $207 \mathrm{~km}$ on the Tibetan Plateau and continued to dominate up to $1200 \mathrm{~km}$.

On broader scales, it appears that stochastic processes have relatively less influence on microbial assemblages, and determinism instead dominates [61]. At the local scale across variable environments, Schmidt et al. [62] reported that deterministic processes play a dominant role in bacterial community assembly, with bacteria exhibiting strong habitat associations. Our present study further confirms that stochasticity tends to dominate at a more local scale and becomes progressively more important at larger spatial scales. Even the smallest scale in the present study is relatively broad compared with many previous studies, and it would be interesting to expand the scale range to include samples separated by centimeters or meters and ranging up to thousands of kilometers.

What deterministic environmental factors produce the observed patterns? Mantel test analysis revealed that the major deterministic factors causing trends in soil bacterial community composition are soil $\mathrm{pH}$ and to a slightly lesser extent $\mathrm{Mg}, \mathrm{Ca}, \mathrm{TP}, \mathrm{TK}$, and climate factors (MAP-mean annual precipitation, MAT-mean annual temperature; Additional file 2: Tables S4 and S7). It is clear that various trace elements could influence the microbial diversity and community, such as the compound variable $\mathrm{Cu} / \mathrm{As} / \mathrm{Ca}$ [63], mixtures of $\mathrm{Cu}^{2+}, \mathrm{Zn}^{2+}, \mathrm{Fe}^{2+}$ and $\mathrm{I}^{-}$[64], $\mathrm{Fe}$ [65] and $\mathrm{Ca}$ [66]. Taking $\mathrm{Mg}$ and $\mathrm{Ca}$ for example, SagovaMareckova et al. found that the abundance of soil Actinobacteria was positively correlated with these two factors [67]. While some of these factors, especially $\mathrm{pH}$, have a detectable influence even at scales where $\beta$ NTI suggests that stochasticity dominates, their influence is stronger at larger scales. Other studies have reported similar results [17, 18]. It is interesting that $\beta$ NTI jumps at scales beyond about $800 \mathrm{~km}$. As shown in the soil $\mathrm{pH}$ map of the study region (Additional file 1: Figure S7A; Additional file 2: Table S8), any linear distance of $800 \mathrm{~km}$ crosses between the large alkaline soil area of the northern section of the NCP, and the acidic soil area of the south (not obvious for MAP and MAT maps; Additional file 1: Figure S7B and C). It appears logical that there will be a dramatic increase in the role of determinism when the sampling scale is sufficient to include communities from both $\mathrm{pH}$ environments in the same calculation of $\beta$ NTI. 
How much of the variation in soil microbial community can be explained? In our study, $77.5 \%$ of variation in the soil microbial community could not be explained by soil variables $(16.2 \%)$ and spatial parameters (6.3\%), consistent with a previous study in which only $27 \%$ of the variation in a Burkholderia ambifaria bacterial community could be explained by environmental and spatial factors through a patchy agricultural field [68]. Similarly, in a forest soil, Zhou et al. [69] found that $20.7 \%$ of the soil microbial community composition could be explained by environmental heterogeneity, $18.3 \%$ by geographic distance, and $5.8 \%$ by their interactions. In Arctic soils, Shi et al. [43] found that only $12 \%$ of variation in functional community composition could be explained by spatial distance and only $3 \%$ by identified environmental factors. The reasons for unexplained variation include phylotype immigration, mutations, and extinction rates, all classified as stochastic process [14, 70]. By contrast, based on niche theory, deterministic processes are predominant even at larger scales, while stochastic process (unmeasured variables) are also of primary importance and contribute to variation in soil microbial communities [60]. This suggests that both deterministic and stochastic factors affecting microorganisms should be considered when regulating and managing the soil microbial community to improve soil fertility and production in cropland systems.

\section{Conclusions}

Our study revealed that the relative importance of stochasticity and determinism in soil bacterial communities varies according to spatial scale, with determinism playing a greater role at broader scales in the arable land of the North China Plain. Likewise, in natural ecosystems of the Tibetan Plateau, stochastic processes typically dominate on a small scale, while determinism plays a greater role at medium and broader scales. These results are as might be expected given the greater environmental heterogeneity that exists at broader scales, which affords greater opportunities for niche differences to support distinct communities. However, it is important to confirm such predictions through testing and observation. We covered a broad range of spatial scales in a relatively simple, standardized system, allowing trends to emerge more clearly. It would be interesting to extend such studies to a broader range of spatial scales, especially the very local scale $(<1 \mathrm{~km})$ not studied in this work, and also to natural and semi-natural systems.

Large-scale intensive cultivation with high chemical input homogenizes soil structure and quality to a certain extent, resulting in soil conditions that are similar at a relatively small scale. This may explain why deterministic processes dominated at a large scale. These anthropogenic practices ultimately reduce ecosystem services such as pollination, resulting in a reduction in grain yield. Our findings remind us to not only consider soil microbial conditioning during agricultural soil management, for example in the targeting of fertilizers, but also to focus on scale effects and use different approaches at different scales.

\section{Methods}

\section{Sample collection}

The NCP region in this study extends from $30^{\circ} \mathrm{N}$ to $40^{\circ}$ $\mathrm{N}$, and $109^{\circ} \mathrm{E}$ to $122^{\circ} \mathrm{E}$. This area is an important agricultural area in China and has supported 40 years of winter wheat and summer corn rotation [71]. The topography of this area is flat, and the altitude of most parts is below $50 \mathrm{~m}$ above sea level. The region has a warm temperate monsoon climate, with an average annual temperature of $8-15{ }^{\circ} \mathrm{C}$, and the average annual precipitation is $500-1000 \mathrm{~mm}$. The soils from all the sampling sites were classified as Ochric Aquic Cambosols (Chinese soil taxonomy) in our study [48].

To survey the soil bacterial distribution of wheat fields across the NCP, we collected 243 soil samples from 27 sites (Additional file 1: Figure S8) during the winter season (the 20th to the 30th of November 2014). At each site, we sampled nine plots about $3.3 \mathrm{~km}$ apart within $100 \mathrm{~km}^{2}$ (Additional file 1: Figure S8) and collected 12 cores per plot at a depth of $0-15 \mathrm{~cm}$, which were subsequently combined as single samples and stored in ice boxes. Our locations covered 300,000 $\mathrm{km}^{2}$ (Additional file 1: Figure S7; Additional file 2: Table S8) from main yield wheat districts. All soil samples were delivered on ice $\left(4^{\circ} \mathrm{C}\right)$ to the laboratory as soon as possible, where they were sieved through a $2 \mathrm{~mm}$ mesh and divided into two subsamples, with half stored at $4{ }^{\circ} \mathrm{C}$ for determination of physical and chemical properties, and the other half stored at $-20{ }^{\circ} \mathrm{C}$ prior to DNA extraction.

\section{Soil biogeochemical analysis}

Soil $\mathrm{pH}$ was determined using a fresh soil to water ratio of 1:5 using a $\mathrm{pH}$ monitor (Thermo 0rion-868, MA, USA). Soil moisture was measured gravimetrically after a 16 -h desiccation at $105^{\circ} \mathrm{C}$. Soil samples for $\mathrm{C}$ and $\mathrm{N}$ analyses were air dried ( $2 \mathrm{~mm}$ mesh), handpicked to remove plant litter and fine roots, and ground. Total soil $\mathrm{C}$ and $\mathrm{N}$ content for each plot were determined by combustion (2400 II CHNS/0 Elemental 1 Analyzer, PerkinElmer, Boston, MA, USA). Dissolved organic carbon (DOC) and dissolved total nitrogen (DTN) were extracted by adding $50 \mathrm{ml}$ of $0.5 \mathrm{MK}_{2} \mathrm{SO}_{4}$ to $10 \mathrm{~g}$ fresh soil, shaking for $1 \mathrm{~h}$, and vacuum filtering through a G4 glass fiber filter with a pore space of $1.2 \mu \mathrm{m}$ (Fisher). DOC and DTN were determined using a total organic carbon-total nitrogen (TOC-TN) analyzer (Shimadzu, Kyoto, Japan). Ammonium $\left(\mathrm{NH}_{4}^{+}\right)$and nitrate $\left(\mathrm{NO}_{3}^{-}\right)$ 
concentrations in extracts were assessed colorimetrically by automated segmented flow analysis (AAIII; Bran and Luebbe, Germany) using the salicylate/dichloroisocyanuric acid and cadmium column/sulfanilamide reduction methods, respectively. Through $\mathrm{HF}$ and $\mathrm{HClO}_{4}$ digestion, total potassium (TK) was determined by flame photometry (FP640, INASA, China), while total phosphorus (TP) was determined using the molybdenum blue method. Available potassium (AK) was determined in $1 \mathrm{M}$ ammonium acetate extracts by flame photometry (FP640, INASA, China). Soil available phosphorus (AP) was extracted by $0.5 \mathrm{M} \mathrm{NaHCO}_{3}$ and determined using the molybdenum blue method. Organic carbon was determined according to potassium dichromate oxidation titration. Soil electric conductivity was determined by a conductivity monitor using a dry soil to water ratio of 1:5 (Thermo 0rion-868, MA, USA). Soil samples were air dried and homogenized by grinding in an agate mortar and then passed through a $0.149 \mathrm{~mm}$ sieve to analyze the elements. These samples $(\sim 0.4-0.5 \pm 0.0001 \mathrm{~g})$ were digested with nitric acid $\left(\mathrm{HNO}_{3}\right)$, hydrofluoric acid (HF), and perchloric acid $\left(\mathrm{HClO}_{4}\right)(5 \mathrm{~mL}: 10 \mathrm{~mL}: 5 \mathrm{~mL})$ on a hot plate. Soil total $\mathrm{Mg}, \mathrm{Ca}, \mathrm{K}$, and Fe were measured with an ICP-AES Optima 8000 (Perkin-Elmer, Waltham, MA, USA), while total $\mathrm{Cd}$, chromium $(\mathrm{Cr}), \mathrm{Mn}$, cop$\operatorname{per}(\mathrm{Cu}), \mathrm{Zn}$, plumbum $(\mathrm{Pb})$, and As were measured with an HPLC-ICP-MS (7700X, Agilent, USA). A certified soil reference material (GBW07408, National Research Center for Certified Reference Materaials, China) were used to ensure that the accuracy of the analytical data and the accuracy ranged from 93.9 to $107.4 \%$. All soil variables are described in Additional file 2: Table S9.

\section{Molecular analyses}

Total soil nucleic acids from each plot were extracted and purified using a Power Soil DNA kit (MO BIO, Carlsbad, CA, USA) followed by an Ultra Clean 15 DNA purification kit (MO BIO, Carlsbad, CA, USA) and stored at $40{ }^{\circ} \mathrm{C}$. DNA concentration was quantified with a Nano Drop ND-1000 spectrophotometer (Thermo Scientific, USA), and DNA was diluted to approximately $25 \mathrm{ng} / \mu \mathrm{l}$ with distilled water and stored at $-20{ }^{\circ} \mathrm{C}$ until use. V4 hyper-variable regions were amplified using a common primer set (515F, 5' -GTGCCAGCMGCCGCGGTAA-3'; 806R, 5' -GGACTACHVGGGTWTCTAAT-3') combined with adapter sequences and barcode sequences (most bacteria and a few archaea) [72]. Each sample was amplified in triplicate in a $50 \mu \mathrm{l}$ reaction under the following conditions: 30 cycles of denaturation at $94{ }^{\circ} \mathrm{C}$ for $30 \mathrm{~s}$, annealing at $55{ }^{\circ} \mathrm{C}$ for $30 \mathrm{~s}$, and extension at $72{ }^{\circ} \mathrm{C}$ for $30 \mathrm{~s}$, with a final extension at $72{ }^{\circ} \mathrm{C}$ for $10 \mathrm{~min}$. PCR products from each sample were pooled and purified using a QIAquick PCR purification kit (Qiagen) and quantified using a NanoDrop ND-1000 spectrophotometer (Thermo Scientific,
USA). PCR products were combined in equimolar ratios in a single tube and run on two lanes of a $2 \times 151$ bp sequencing run on an Illumina MiSeq [73].

Raw data were processed and analyzed as previously described using the QIIME software package [68] and following the workflow at http://nbviewer.ipython.org/ github/biocore/qiime/blob/1.9.1/examples/ipynb/illumina overview_tutorial.ipynb. Briefly, sequences were quality filtered (max value of 0.5) and clustered into 97\% similar phylotypes after removing singleton sequences. The taxonomic identity of each phylotype was identified using the Ribosomal Database Project classifier [74] which was trained on the Greengenes 13_8 16S rRNA database [75]. To rarify all data sets to the same level of sampling effort, 20,005 sequences were randomly selected.

\section{Statistical analyses}

The Faith index was calculated to represent phylogenetic diversity (PD) [76]. OTU-level measurements were assessed by the Shannon index [77]. Rarefied out collections were used to calculate richness (i.e., OTUs, the number of phylotypes), and Chao1 [78] and Simpson [79] indexes were also calculated. These indexes were calculated based on OTU-table and used as $\alpha$-diversity in this study (Additional file 2: Table S10). Pearson correlation between bacterial $\alpha$-diversity indices and soil characteristics were conducted using SPSS 20.0 for Windows. Cluster analysis was performed using the Unweighted Pair Group Method with Arithmetic Mean (UPGMA) clustering method based on Bray-Curtis dissimilarity. Mantel tests were conducted between BrayCurtis distance and soil variables using the vegan package [80] in $\mathrm{R}$ [81]. Corresponding precipitation and temperature data for the NCP area were acquired from www.worldclim.org, based on 1970-2000 mean annual temperature and precipitation. Corresponding mean annual temperature (MAP) and mean annual precipitation values for each site were extracted according to the sampling coordinates. Mantel tests were conducted between Bray-Curtis distance and climate factors using the vegan package [80] in $R$ [81]. The mvpart package in $R$ and Multivariate Regression Tree (MRT) plots were used to identify key environmental variables influencing the community. Non-metric multidimensional scaling analyses were performed using vegan of $\mathrm{R}$ 3.2.0 [81] based on the Bray-Curtis index [82], and soil pH was fitted using vegan in R. Distance decay curves were calculated according to Nekola and White [83] using spatial distance (calculated by geographical coordinates) and microbial community similarity among samples. Environmental distance fitted to microbial community similarity was calculated using soil variables based on the Euclidean method [84]. 


\section{Process analysis}

In order to evaluate the phylogenetic community composition within each sample, mean nearest taxon distance (MNTD) for each sample was calculated $[4,55]$. To identify processes driving soil microbial community composition within a sample, the ses.MNTD (standardized effect size measure MNTD), which quantifies the number of standard deviations of the observed MNTD values, was used to test for niche or dispersal limitations [85]. When ses.MNTD values are negative and quantiles are low $(P<0.05)$, co-occurring species are more affected by phylogenetic clustering than dispersal limitation. In this study, the ses.MNTD is the Nearest Taxon Index (NTI). By contrast, positive values and high quantiles $(P>0.95)$ indicates that co-occurring species are more affected by dispersal limitation than phylogenetic clustering [85]. $\beta$ MNTD and $\beta$ NTI (standard deviations of $\beta$ MNTD) were calculated as previously described [4]. Briefly, if $\beta$ NTI values are $\beta$ NTI $>2$ or $\beta$ NTI $<-2$, deterministic processes are important in shaping the community composition across all sites, whereas if $\beta$ NTI values are between -2 and 2 , stochastic processes will play an important role. All MNTD analyses were conducted using Picante 1.2-0 [86] in $\mathrm{R}$ (http://www.r-project.org). The standardized effect size measure (ses.MNTD) quantifies the number of standard deviations of the observed MNTD from the mean of the null distribution (999 randomizations).

In order to confirm whether the niche or neutral processes determined the soil microbial structure within a sample, the zero-sum multinomial (ZSM) method was employed [16]. According to neutral theory, the rank species abundance distribution is consistent with ZSM [14]. Additionally, according to niche theory, preemption, broken stick, log-normal, and Zipf-Mandlebrot models [87-89] were selected to identify the rank species abundance distributions and were calculated using the "radfit" function in the vegan package in $\mathrm{R}[81,90]$. The ZSM model was conducted using TeTame [91]. All models were compared based on the Akaike Information Criterion (AIC), which measures the relative quality of a statistical model. AIC values were calculated based on the equation $\mathrm{AIC}=-2 \log$-likelihood $\mathrm{p} 2 \times$ npar, where npar is the number of parameters in the fitted model [92]. A lower AIC value indicates a better fit of the model to the empirical data [93].

In order to investigate the relative role of deterministic or stochastic processes at different spatial scales, the Principal Coordinates of Neighbor Matrices (PCNM) analytical approach was performed, which is able to deconvolute total spatial variation into a discrete set of explanatory spatial scales [94]. In addition, the PCNM method was used to classify large, medium, and small spatial scales [43] by first separating the whole sampling site into different spatial scales, then pair to pair comparison was used to form groups based on $\beta \mathrm{NTI}$ values. Due to the distribution of $\beta$ NTI values within each scale were skewed, Kruskal-Wallis method was chose to test the differences in $\beta$ NTI median values across the scales $[4,95]$. The tested result showed that $\beta$ NTI median values were significantly different across the spatial scales (chi-square $=427.1132, \mathrm{df}=15, p \ll 0.0001$, wheat field; chi-square $=366.0829, \mathrm{df}=14, p \ll 0.0001$, Tibetan Plateau samples).The procedure for determining the relative role of deterministic and stochastic process in each spatial scale was presented by a conceptual diagram (Additional file 1: Figure S9). We also compared the natural soils on the Tibetan Plateau (covered more than $1,000,000 \mathrm{~km}^{2}$ and all of the major climate zones and grassland types) to the agricultural soils in North China Plain. The Tibetan Plateau sites description and the high throughput data analysis were well described by Jing et al. [96]. Briefly, we sampled 180 soil samples $(0-5 \mathrm{~cm}, 60$ study sites, three plots, $40 \mathrm{~m}$ apart in each site) during growing season of 2011. In each plot, 5-7 soil cores $(5 \mathrm{~cm}$ in diameter) were collected and mixed as one sample. For the locations' information, please see Additional file 2: Table S11. The investigation of the relative role of deterministic or stochastic processes at different spatial scales for Tibetan Plateau soils followed the conceptual diagram (Additional file 1: Figure S9).

\section{Contribution analysis}

In order to evaluate the effects of space and environmental soil parameters on soil bacterial distribution, variance partitioning analysis was conducted by combining the PCNM output with a modified variation partitioning diagram, as described by Legendre et al. [97] and Borcard et al. [36], using the "varpart" function in the vegan package [90]. Each part of the variation partitioning diagram is described in Additional file 1: Figure S9 of a previous report [43]. All analyses were performed using $\mathrm{R}$ version 3.0.1.

\section{Additional files}

\footnotetext{
Additional file 1: Figure S1. Relative abundance of dominant bacterial phyla/classes and archaeal phyla across the soils (North China Plain). Soils are grouped by sampling sites. Figure S2. Variation of the standardized effect sizes of MNTD (ses.MNTD) of bacterial communities within each site in the North China Plain soils. Figure S3. Boxplots of AIC values for six rank abundance distribution models. AIC, Akaike Information Criterion; ZS, zero-sum multinomial; Nu, Null model; Pr, Pre-emption; Lo, Log normal; Zipf, Zi; Ma, Mandlebrot (North China Plain). Figure S4. Distance-decay curves of similarity for bacterial communities. Environmental distance (presented as a color gradient) were fitted to bacterial community similarity (North China Plain). Figure S5. Scatter plot of $\beta$ NTI values grouped by spatial scales (Tibetan Plateau). Dash blue lines represent the median value of each scale. Figure S6. Multivariate Regression Tree (MRT) analysis indicating soil $\mathrm{pH}$ constraints on soil bacterial community (North China Plain). Figure S7. Soil sampling locations based on soil $\mathrm{pH}(\mathrm{A})$, precipitation (B), and temperature $(\mathrm{C})$ maps. Maps including corresponding soil $\mathrm{pH}$ across
} 
the NCP were acquired from http://www.soil.csdb.cn/, and corresponding annual mean precipitation and temperature data were acquired from www.worldclim.org for years 1970 to 2000. Figure S8. Locations of sampling map and quadrat sets of North China Plain. Figure S9. The conceptual diagram for determining the relative role of deterministic and stochastic process in each spatial scale. (DOC $6052 \mathrm{~kb}$ )

Additional file 2: Table S1. Relative average abundance of bacterial phyla classified with RDPII taxonomy using the Greengenes database (http://greengenes.lbl.gov/) across all soils. (North China Plain). Table S2. Relative average abundance of dominant bacterial group classified with RDPII taxonomy using the Greengenes database (http:/greengenes.|bl.gov/) across all soils (North China Plain). Table S3. Variation in median $\beta N T I$ values at different spatial scales and the relative contribution (\%) of deterministic and stochastic process in each spatial scale (Tibetan Plateau). Table S4. Correlation between soil characteristics and bacterial community structure determined by Mantel tests $(P<0.05$, permutation $=999)$ (North China Plain). Table S5. Variance of bacterial community explained by soil characteristics (North China Plain). The percentage of explained variance of each variable was calculated by DistLM forward3 $(P<0.05$, permutation $=$ 999). Significant values are in bold. For the abbreviations, please see Table S4. Table S6. Pearson correlation between bacterial a-diversity indices and soil characteristics with rarefaction of 20,005 sequences per sample (North China Plain). Significant values are in bold. For the abbreviations, please see Table S4. Table S7. Correlation between climate factors and bacterial community structure determined by Mantel tests $(P<0.05$, permutation $=999)$ (North China Plain). Significant values are in bold. Table S8. Geographic coordinates of sampling sites. Coordinates are shown using the WGS-84 coordinate system. Table S9. Soil physiochemical characteristics among all sampling sites. Values in brackets denote standard deviation (North China Plain). For the abbreviations, please see Table S4. Table S10. Alpha diversity of all sampling sites with rarefaction of 20,005 sequences per sample (North China Plain). Table S11. Location information of sampling sites in Tibetan Plateau. In addition, the followed annotations and the abbreviations of tables can be the footnotes of the tables. (ZIP $551 \mathrm{~kb}$ )

\section{Acknowledgements}

We thank L. H. Wang, C. C. Shen, K. K. Fan, Y. S. Jia, and H. F. Wang for their assistance in soil sampling and lab analyses.

\section{Funding}

This work was supported by the Strategic Priority Research Program (XDB15010101) of the Chinese Academy of Sciences, the National Key Research and Development Program of China (2017YFD0200604), the National Program on Key Basic Research Project (2014CB954002), the National Natural Science Foundation of China $(41701298,41371254)$, and the China Biodiversity Observation Networks (Sino BON).

\section{Availability of data and materials}

The soil bacteria dataset has been deposited in the NCBI Sequence Read Archive under accession number: SRP100578,

\section{Authors' contributions}

YS and YTL contributed equally to this work. YS performed laboratory experiments, evaluated the data, and wrote the manuscript. YTL performed data analysis and wrote the manuscript. XJX, RBS, TY, DH, KPZ, and YYN pre-processed the samples and provided the soil metadata. JMA provided general overview and perspectives on the use of stochasticity data and wrote the manuscript. YGZ provided input for experimental design and manuscript writing. HYC initiated and designed the study, evaluated experiments, and wrote the manuscript. All authors read and approved the final manuscript.

\section{Ethics approval and consent to participate}

Not applicable.

\section{Consent for publication}

Not applicable.

\section{Competing interests}

The authors declare that they have no competing interests.

\section{Publisher's Note}

Springer Nature remains neutral with regard to jurisdictional claims in published maps and institutional affiliations.

\section{Author details}

${ }^{1}$ State Key Laboratory of Soil and Sustainable Agriculture, Institute of Soil Science, Chinese Academy of Sciences, 71 East Beijing Road, Nanjing 210008, China. ${ }^{2}$ Key Laboratory of Urban Environment and Health, Institute of Urban Environment, Chinese Academy of Sciences, Xiamen 361021, China. ${ }^{3}$ School of Water, Energy and Environment, Cranfield University, Cranfield MK46 OAL, UK.

Received: 3 November 2017 Accepted: 19 January 2018

Published online: 05 February 2018

\section{References}

1. Huber JA, Welch DBM, Morrison HG, Huse SM, Neal PR, Butterfield DA, et al. Microbial population structures in the deep marine biosphere. Science. 2007;318:97-100.

2. Logares R, Audic S, Bass D, Bittner L, Boutte C, Christen R, et al. Patterns of rare and abundant marine microbial eukaryotes. Curr Biol. 2014;24:813-21.

3. Chu HY, Sun HB, Tripathi BM, Adams JM, Huang R, Zhang YJ, et al. Bacterial community dissimilarity between the surface and subsurface soils equals horizontal differences over several kilometers in the western Tibetan Plateau. Environ Microbiol. 2016;18:1523-33.

4. Stegen JC, Lin X, Konopka AE, Fredrickson JK. Stochastic and deterministic assembly processes in subsurface microbial communities. ISME J. 2012;6: 1653-64.

5. Dini-Andreote F, Stegen JC, Van-Elsas JD, Salles JF. Disentangling mechanisms that mediate the balance between stochastic and deterministic processes in microbial succession. Proc Natl Acad Sci U S A. 2015;112:1326-32.

6. Ge Y, He JZ, Zhu YG, Zhang JB, Xu ZH, Zhang LM, et al. Differences in soil bacterial diversity: driven by contemporary disturbances or historical contingencies? ISME J. 2008:2:254-64.

7. Levine UY, Teal TK, Robertson GP, Schmidt TM. Agriculture's impact on microbial diversity and associated fluxes of carbon dioxide and methane. ISME J. 2011;5:1683-91.

8. Rodrigues JLM, Pellizari VH, Mueller R, Baek K, Jesus ED, Paula FS, et al. Conversion of the Amazon rainforest to agriculture results in biotic homogenization of soil bacterial communities. Proc Natl Acad Sci U S A. 2013;110:988-93.

9. Heijden MGAVD, Klironomos JN, Ursic M, Moutoglis P, Streitwolf-Engel R, Boller T, et al. Mycorrhizal fungal diversity determines plant biodiversity, ecosystem variability and productivity. Nature. 1998;396:69-72.

10. Delgado-Baquerizo M, Maestre FT, Reich PB, Jeffries TC, Gaitan JJ, Encinar D, et al. Microbial diversity drives multifunctionality in terrestrial ecosystems. Nat Commun. 2016:7:10541.

11. Putten WHVD. Belowground drivers of plant diversity. Science. 2017;355: 6321

12. Tokeshi M. Niche apportionment or random assortment : species abundance patterns revisited. J Anim Ecol. 1990;59:1129-46.

13. Baas-Becking L. Geobiologie of Inleiding tot de Milieukunde. The Hague: Van Stockum \& Zoon; 1934.

14. Hubbell SP. The unified neutral theory of biodiversity and biogeography, Monographs in population biology, vol. 32. Princeton: Princeton University Press; 2001.

15. Chave J. Neutral theory and community ecology. Ecol Lett. 2004;7:241-53.

16. McGill BJ, Maurer BA, Weiser MD. Empirical evaluation of neutral theory. Ecology. 2006;87:1411-23.

17. Fierer $\mathrm{N}$, Jackson RB. The diversity and biogeography of soil bacterial communities. Proc Natl Acad Sci USA. 2006;103:626-31.

18. Chu HY, Fierer N, Lauber CL, Caporaso JG, Knight R, Grogan P. Soil bacterial diversity in the Arctic is not fundamentally different from that found in other biomes. Environ Microbiol. 2010;12:2998-3006.

19. Lauber $\mathrm{CL}$, Hamady M, Knight R, Fierer N. Pyrosequencing-based assessment of soil pH as a predictor of soil microbial community structure at the continental scale. Appl Environ Microbiol. 2009:75:5111-20.

20. Shen $C C$, Xiong JB, Zhan HY, Feng $Y Z$, Lin $X G$, Li XY, et al. Soil pH drives the spatial distribution of bacterial communities along elevation on Changbai Mountain. Soil Biol Biochem. 2013;57:204-11. 
21. Shi Y, Adams JM, Ni YY, Yang T, Jing X, Chen LT, et al. The biogeography of soil archaeal communities on the eastern Tibetan Plateau. Sci Rep. 2016; https://doi.org/10.1038/srep38893.

22. Orwin KH, Wardle DA, Greenfield LG. Ecological consequences of carbon substrate identity and diversity in a laboratory study. Ecology. 2006;87:58093.

23. Hansel CM, Fendorf S, Jardine PM, Francis CA. Changes in bacterial and archaeal community structure and functional diversity along a geochemically variable soil profile. Appl Environ Microbiol. 2008;74:1620-33.

24. Xiong JB, Wu LY, Tu SX, Van Nostrand JD, He ZL, Zhou JZ, et al. Microbial communities and functional genes associated with soil arsenic contamination and the rhizosphere of the arsenic-hyper accumulating plant Pterisvittata L. Appl Environ Microbiol. 2010;76:7277-84.

25. Zhang XF, Xu SJ, Li CM, Zhao L, Feng HY, Yue GY, et al. The soil carbon/ nitrogen ratio and moisture affect microbial community structures in alkaline permafrost-affected soils with different vegetation types on the Tibetan plateau. Res Microbiol. 2014;165:128-39.

26. Miller SR, Strong AL, Jones $\mathrm{KL}$, Ungerer MC. Bar-coded pyrosequencing reveals shared bacterial community properties along the temperature gradients of two alkaline hot springs in Yellowstone National Park. Appl Environ Microbiol. 2009;75:4565-72.

27. Shi Y, Xiang XJ, Shen CC, Chu HY, Neufeld JD, Walker VK, et al. Vegetationassociated impacts on Arctic tundra bacterial and micro-eukaryotic communities. Appl Environ Microbiol. 2015;81:482-501.

28. Mitchell RJ, Campbell CD, Chapman SJ, Cameron CM. The ecological engineering impact of a single tree species on the soil microbial community. J Ecol. 2010;98:50-61.

29. Kowalchuk GA, Buma DS, Boer WD, Klinkhamer P, Van Veen JA. Effects of above-ground plant species composition and diversity on the diversity of soil borne microorganisms. Antonie Van Leeuwenhoek. 2002;81:509-20.

30. Eisenhauer N, Bessler H, Engels C, Gleixner G, Habekost M, Milcu A, et al. Plant diversity effects on soil microorganisms support the singular hypothesis. Ecology. 2010;91:485-96.

31. Knief C, Ramette A, Frances L, Alonso-Blanco C, Vorholt JA. Site and plant species are important determinants of the Methylobacterium community composition in the plant phyllosphere. ISME J. 2010;4:719-28.

32. Zhang CB, Wang J, Liu WL, Zhu SX, Ge HL, Chang SX, et al. Effects of plant diversity on microbial biomass and community metabolic profiles in a fullscale constructed wetland. Ecol Eng. 2010;36:62-8.

33. Chu HY, Neufeld JD, Walker VK, Grogan P. The influence of vegetation type on the dominant soil bacteria, archaea, and fungi in a low Arctic tundra landscape. Soil Sci Soc Am J. 2011;75:1756-65.

34. Cho JC, Tiedje JM. Biogeography and degree of endemicity of fluorescent Pseudomonas strains in soil. Appl Environ Microbiol. 2000;66:5448-56.

35. Whitaker RJ, Grogan DW, Taylor JW. Geographic barriers isolate endemic populations of hyperthermophilic archaea. Science. 2003;301:976-8.

36. Borcard D, Legendre P, Drapeau P. Partialling out the spatial component of ecological variation. Ecology. 1992;73:1045-55.

37. Martiny JBH, Bohannan BJM, Brown JH, Colwell RK, Fuhrman JA, Green JL, et al. Microbial biogeography: putting microorganisms on the map. Nat Rev Microbiol. 2006:4:102-12.

38. Ramette A, Tiedje JM. Multiscale responses of microbial life to spatial distance and environmental heterogeneity in a patchy ecosystem. Proc Natl Acad Sci U S A. 2007:104:2761-6.

39. Martiny JBH, Eisen JA, Penn K, Allison SD, Horner-Devine MC. Drivers of bacterial beta diversity depend on spatial scale. Proc Natl Acad Sci U S A. 2011;108:7850-4

40. Franklin RB, Mills AL. Multi-scale variation in spatial heterogeneity for microbial community structure in an eastern Virginia agricultural field. FEMS Microbiol Ecol. 2003:44:335-46.

41. Philippot L, Cuhel J, Saby NPA, Cheneby D, Chronakova A, Bru D, et al. Mapping field-scale spatial patterns of size and activity of the denitrifier community. Environ Microbiol. 2009;11:1518-26.

42. Bru D, Ramette A, Saby NPA, Dequiedt S, Ranjard L, Jolivet C, et al. Determinants of the distribution of nitrogen-cycling microbial communities at the landscape scale. ISME J. 2011;5:532-42.

43. Shi Y, Grogen P, Sun HB, Xiong JB, Yang YF, Zhou JZ, et al. Multi-scale variability analysis reveals the importance of spatial distance in shaping Arctic soil microbial functional communities. Soil Biol Biochem. 2015;86: $126-34$.
44. Stegen JC, Lin XJ, Fredrickson JK, Chen XY, Kennedy DW, Murray CJ, et al. Quantifying community assembly processes and identifying features that impose them. ISME J. 2013;7:2069-79.

45. Wang JJ, Shen J, Wu YC, Tu C, Soininen J, Stegen JC, et al. Phylogenetic beta diversity in bacterial assemblages across ecosystems: deterministic versus stochastic processes. ISME J. 2013;7:1310-21.

46. Mendes LW, Kuramae EE, Navarrete AA, van Veen JA, Tsai SM. Taxonomical and functional microbial community selection in soybean rhizosphere. ISME J. 2014;8:1577-87.

47. Jeong SJ, Ho CH, Piao SL, Kim J, Ciais P, Lee Y, et al. Effects of double cropping on summer climate of the North China Plain and neighbouring regions. Nat Clim Change. 2014;4:615-9.

48. Zhu AN, Zhang JB, Zhao BZ, Cheng ZH, Li LP. Water balance and nitrate leaching losses under intensive crop production with Ochric Aquic Cambosols in North China Plain. Environ Int. 2005:31:904-12.

49. Godfray HCJ, Beddington JR, Crute L, Haddad L, Lawrence D, Muir JF, et al. Food security: the challenge of feeding 9 billion people. Science. 2010;327: 812-8.

50. Piao SL, Ciais $P$, Huang $Y$, Shen ZH, Peng SS, Li JS, et al. The impacts of climate change on water resources and agriculture in China. Nature. 2010; 467:43-51.

51. Yang S. The ten agricultural regions of China. In: Xu G, Peel $L$, editors. The agriculture of China. New York: Oxford University Press; 1991. p. 108-43.

52. National Bureau of Statistics of China. China statistical year book. Beijing: China statistical Press; 1999.

53. Borcard D, Gillet FO, Legendre P. Numerical ecology with R. New York: Springer; 2011.

54. Kembel SW. Disentangling niche and neutral influences on community assembly: assessing the performance of community phylogenetic structure tests. Ecol Lett. 2009:12:949-60.

55. Fine PVA, Kembel SW. Phylogenetic community structure and phylogenetic turnover across space and edaphic gradients in western Amazonian tree communities. Ecography. 2011;34:552-65.

56. Zinger L, Amaral-Zettler LA, Fuhrman JA, Horner-Devine MC, Huse SM, Welch DBM, et al. Global patterns of bacterial beta-diversity in seafloor and seawater ecosystems. PLoS One 2011:6:e24570.

57. Jeraldo P, Sipos M, Chia N, Brulc JM, Dhillon AS, Konkel ME, et al. Quantification of the relative roles of niche and neutral processes in structuring gastrointestinal microbiomes. Proc Natl Acad Sci U S A. 2012; 109:9692-8.

58. Bahram M, Kohout P, Anslan S, Harend H, Abarenkov K, Tedersoo L. Stochastic distribution of small soil eukaryotes resulting from high dispersal and drift in a local environment. ISME J. 2016:10:885-96.

59. Wilson JB. The twelve theories of co-existence in plant communities: the doubtful, the important and the unexplored. J Veg Sci. 2011;22:184-95.

60. Chase JM. Spatial scale resolves the niche versus neutral theory debate. J Veg Sci. 2014:25:319-22.

61. Caruso T, Chan YK, Lacap DC, Lau MCY, Mckay CP, Pointing SB. Stochastic and deterministic processes interact in the assembly of desert microbial communities on a global scale. ISME J. 2011;5:1406-13.

62. Schmidt SK, Nemergut DR, Darcy JL, Lynch R. Do bacterial and fungal communities assemble differently during primary succession? Mol Ecol. 2014:23:254-8.

63. Fuentes S, Ding G-C, Cardenas F, Smalla K, Seeger M. Assessing environmental drivers of microbial communities in estuarine soils of the Aconcagua River in Central Chile. FEMS Microbiol Ecol. 2015;91:fiv110.

64. He YY, Chen ZY, Liu XL, Wang CW, Lu W. Influence of trace elements mixture on bacterial diversity and fermentation characteristics of liquid diet fermented with probiotics under air-tight condition. PLoS One. 2014;9:e114218.

65. Ma B, Wang H, Dsouza M, Lou J, He Y, Dai ZM, et al. Geographic patterns of co-occurrence network topological features for soil microbiota at continental scale in eastern China. ISME J. 2016;10:1891-901.

66. Tedersoo L, Bahram M, Polme S, Koljalg U, Yorou NS, Wijesundera R, et al. Global diversity and geography of soil fungi. Science. 2014;346:1078-87.

67. Sagova-Mareckova M, Omelka M, Kopecky J. Sequential analysis of soil factors related to common scab of potatoes. FEMS Microbiol Ecol. 2017;93:fiw201.

68. Fierer N. Embracing the unknown: disentangling the complexities of the soil microbiome. Nat Rev Microbiol. 2017;15:579-90.

69. Zhou JZ, Kang S, Schadt CW, Garten CT. Spatial scaling of functional gene diversity across various microbial taxa. Proc Natl Acad Sci U S A. 2008;105: 7768-73. 
70. Zhou JZ, Deng Y, Zhang P, Xue K, Liang YT, Van Nostrand JD, et al. Stochasticity, succession, and environmental perturbations in a fluidic ecosystem. Proc Natl Acad Sci U S A. 2014;111:836-45.

71. Chen J, Tang C, Sakura Y, Kondoh A, Yu J, Shimada J, et al. Spatial geochemical and isotopic characteristics associated with groundwater flow in the North China Plain. Hydrol Process. 2004;18:3133-46.

72. Caporaso JG, Lauber CL, Walters WA, Lyons DB, Lozupone CA, Turnbaugh PJ. Global patterns of $16 \mathrm{~s}$ rRNA diversity at a depth of millions of sequences per sample. Proc Natl Acad Sci U S A. 2011;108:4516-22.

73. Caporaso JG, Lauber CL, Walters WA, Lyons DB, Huntley J, Fierer N, et al. Ultra-high-throughput microbial community analysis on the Illumina HiSea and MiSeq platforms. ISME J. 2012;6:1621-4.

74. Wang Q, Garrity GM, Tiedje JM, Cole JR. Naive Bayesian classifier for rapid assignment of rRNA sequences into the new bacterial taxonomy. Appl Environ Microbiol. 2007;73:5261-7.

75. McDonald D, Price MN, Goodrich J, Nawrocki EP, DeSantis TZ, Probst A, et al. An improved Greengenes taxonomy with explicit ranks for ecological and evolutionary analyses of bacteria and archaea. ISME J. 2012;6:610-8.

76. Faith DP. Conservation evaluation and phylogenetic diversity. Biol Conserv. 1992;61:1-10.

77. Shannon CE. A mathematical theory of communication. Bell Syst Tech J. 1948;27:379-423. and 623-56

78. Chao A, Shen TJ. Nonparametric estimation of Shannons index of diversity when there are unseen species in sample. Environ Ecol Stat. 2003;10:429-43.

79. Simpson EH. Measurement of diversity. Nature. 1949;163:688.

80. Dixon P. VEGAN, a package of R functions for community ecology. J Veg Sci. 2003;14:927-30.

81. R Development Core Team. $R$, a language and environment for statistical computing. Vienna: R Foundation for Statistical Computing; 2006.

82. Bray JR, Curtis JT. An ordination of the upland forest communities of southern Wisconsin. Ecol Monogr. 1957;27:326-49.

83. Nekola JC, White PS. The distance decay of similarity in biogeography and ecology. J Biogeogr. 1999;26:867-78.

84. Gentle JE. Matrix Algebra: Theory, Computations, and Applications in Statistics. New York: Springer; 2007. p. 299.

85. Webb CO. Exploring the phylogenetic structure of ecological communities: an example for rain forest trees. Am Nat. 2000;156:145-55.

86. Kembel SW, Cowan PD, Helmus MR, Cornwell WK, Morlon H, Ackerly DD, et al. Picante: R tools for integrating phylogenies and ecology. Bioinformatics. 2010:26:1463-4.

87. Motomura I. On the statistical treatment of communities. Zool Mag. 1932; 44:379-83.

88. MacArthur R. On the relative abundance of bird species. Proc Nat Acad Sci USA. 1957:43:293-5.

89. McGill BJ, Rampal S, Etienne JS, Gray DA, Anderson MJ, Benecha HK, et al. Species abundance distribution: moving beyond single prediction theories to integration within an ecological framework. Ecol Lett. 2007;10:995-1015.

90. Oksanen J, Blanchet FG, Kindt R, Legendre P, Minchin PR, O'Hara RB, Simpson GL, Solymos P, Stevens MHH, Wagner H. 2016. vegan: Community Ecology Package. R package version 2.3-3. [WWW document] https://CRAN. R-project.org/package=vegan.

91. Jabot F, Etienne RF, Chave J. Reconciling neutral community models and environmental filtering: theory and an empirical test. Oikos. 2008;117: 1308-20.

92. Feinstein LM, Blackwood CB. Taxa-area relationship and neutral dynamics influence the diversity of fungal communities on senesced tree leaves. Environ Microbiol. 2012;14:1488-99.

93. Dumbrell AJ, Nelson M, Helgason T, Dytham C, Fitter AH. Relative roles of niche and neutral process in structuring a soil microbial community. ISME J. 2010;: :337-45

94. Borcard D, Legendre P. All-scale spatial analysis of ecological data by means of principal coordinates of neighbour matrices. Ecol Model. 2002;153:5-68.

95. Wallis K. Use of ranks in one-criterion variance analysis. J Am Stat Assoc. 1952:47:583-621.

96. Jing $X$, Sanders NJ, Shi Y, Chu HY, Classen AT, Zhao K, Chen LT, Shi Y, Jiang YX, He JS. The links between ecosystem multifunctionality and above- and belowground biodiversity are mediated by climate. Nat Commun. 2015;6: 8159 .

97. Legendre P, Legendre L. Numerical ecology. Translated and revised from the second French (1984) edition. Second English edition. Developments in Environmental Modelling 20. Amsterdam: Elsevier Science B.V; 1998.

\section{Submit your next manuscript to BioMed Central and we will help you at every step:}

- We accept pre-submission inquiries

- Our selector tool helps you to find the most relevant journal

- We provide round the clock customer support

- Convenient online submission

- Thorough peer review

- Inclusion in PubMed and all major indexing services

- Maximum visibility for your research

Submit your manuscript at www.biomedcentral.com/submit
Biomed Central 